\title{
Analisis Pengaruh Konfigurasi Fin Pada Stern Terhadap Kemampuan Hydro-Acoustic
}

\author{
Robi Wahyudi, I Ketut Aria Pria Utama \\ Departemen Teknik Perkapalan, Fakultas Teknologi Kelautan, Institut Teknologi Sepuluh Nopember \\ (ITS) \\ e-mail:kutama@na.its.ac.id
}

\begin{abstract}
Abstrak - Kapal selam modern memiliki tingkat kebisingan yang rendah, atau lebih dikenal dengan istilah kemampuan hydroacoustic yang baik. Dalam peperangan tingkat kebisingan menentukan sejauh mana radar musuh mampu mendeteksi keberadaannya, semakin besar kebisingan yang ditimbulkan semakin mudah musuh untuk menganalisis jenis, karakter, posisi, bahkan ukuran kapal selam yang kita gunakan. Oleh karenanya, Besarnya kebisingan ini sangat penting untuk dianalisis pada tahap awal desain. Penelitian ini dimaksudkan untuk mengkaji pengaruh konfigurasi fin yang terdapat di depan propeller dengan jumlah daun propeller. Konfigurasi fin akan menimbulkan wake yang berbeda, sehingga propeller yang bekerja di daerah wake kapal,akan mengalami fluktuasi beban kerja yang berbeda dan pada akhirnya akan menghasilkan kebisingan yang berbeda. Variasi konfigurasi yang dilakukan yaitu 3, 4, dan 5 fin. Dari hasil simulasi didapatkan nilai tertinggi yang terjadi pada konfigurasi 3 fin sebesar $137 \mathrm{~dB}$ re $1 \mu \mathrm{Pa}, 1 \mathrm{~m}$. Pada konfigurasi 4 fin sebesar $112 \mathrm{~dB}$ re $1 \mu \mathrm{Pa}, 1 \mathrm{~m}$. Sedangkan pada konfigurasi 5 fin sebesar $132 \mathrm{~dB}$ re $1 \mu \mathrm{Pa}, 1 \mathrm{~m}$.
\end{abstract}

Kata Kunci-Kapal Selam, Konfigurasi Fin, Wake, HydroAcoustic.

\section{PENDAHULUAN}

K APAL merupakan teknologi unggul yang hanya segilintir negara yang mampu membangunnya, keberadaannya sangat penting bagi keutuhan suatu negara, banyak teknologi pendukung yang terus dikembangkan untuk meningkatkan performa kapal selam. Mulai dari kemampuan radar untuk mendeteksi kemungkinan keberadaan musuh, mesin penggerak bertenaga nuklir, penggunaan material terbaru yang mampu menyerap emisi radar yang dihasilkan pihak musuh. Namun perangkat tersebut masih belum cukup untuk meningkatkan performanya, karena adanya gelombang yang diemisikan oleh kapal selam itu sendiri, seperti gelombang suara yang menimbulkan kebisingan.

Kebisingan pada kapal selam dapat ditimbulkan oleh mesin (machinery noise), perputaran propeller (propeller noise), lapisan batas/aliran (boundary layer/flow noise), peralatan kelistrikan (electrical noise). Dari semua gelombang yang diemisikan ini, hanya dua jenis yang sangat berpengaruh pada suatu kapal selam yaitu akibat pergerakan aliran/lapisan batas (boundary layer/flow noise), yang dominan pada kecepatan rendah (<25 knots)dan perputaran propeller (propeller noise)[1], yang dominan pada kecepatan tinggi ( $>25$ knots). Kebisingan propeller memiliki porsi yang besar terhadap kebisingan pada kecepatan tinggi [2] , hal ini bukan hanya disebabkan oleh jumlah daun, kecepatan putar (rpm) namun juga dipengaruhi bentuk aliran yang masuk ke propeller, karena propeller bekerja di aliran yang sudah terinterferensi bentuk lambung dan buritan (wake) sehingga variasi bentuk buritan akan sangat berpengaruh terhadap wake yang ditimbulkan sehingga memengaruhi kebisingan yang dihasilkan [3]. Ketika jumlah fin/appendages yang berada didepan propeller memiliki jumlah yang sama akan terjadi tingkat kebisingan yang penting untuk ditinau dibanding jumlah fin dan daun propeller yang berbeda

Oleh karena itu, penulis melakukan peninjauan akan kebisingan yang diakibatkan konfigurasi fin di depan propeller dengan memvariasikan fin yang berada di depan propeller menggunakan 3, 4, dan 5 fin dengan propeller 4 daun sehingga dapat diketahui perbandingan jumlah fin dengan jumlah daun pengaruhnya terhadap kemampuan hydro-acousticnya.

\section{II.DASAR TEORI}

\section{A. Kapal Selam}

Kapal merupakan kendaraan yang dibuat untuk keperluan khusus dapat digunakan untuk militer, pengeboran minyak, wisata bawah laut. Secara keseluruhan bentuk lambung kapal selam terbagi menjadi 2 macam, seperti tetesan air (teardrop shape) dan bagian tengah sejajar (Parallel middle body). Sail dan rudder berpenampang foil, rudder buritan tepat berada di depan propeller sehingga secara langsung aliran yang melalui propeller harus mengenai rudder terlebih dahulu.

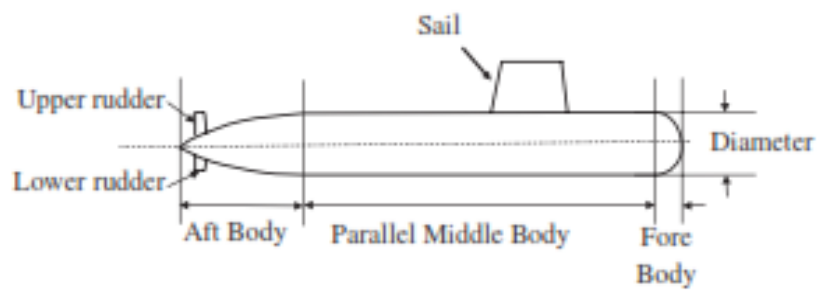

Gambar 1. Geometri kapal selam

\section{B. Konsep Kebisingan}

Kapal selam saat beroperasi akan menimbulkan kebisingan yang ditransmisikan ke lingkungan, kebisingan ini disebabkan oleh permesinan, kelistrikan, aliran dilambung, propeller. Sumber kebisingan tertinggi ialah aliran dan propeller. Lapisan 
batas fluida yang berada di sekitar lambung saat beroperasi akan mengalami transisi aliran laminar menjadi turbulen, hal ini terjadi akibat banyak hal termasuk kurvatur lambung kapal ,tingkat kekasaran ,perbedaan tekanan. Penurunan percepatan gerak fluida secara berlanjut akan menimbulkan pemisahan aliran terhadap lambung, aliran yang berada di sekitar lambung bergerak menjauh dan kekosongan ini diisi oleh aliran yang berada di luar daerah lapisan batas,terjadi baik pada aliran laminar maupun turbulen [4][5]. Pemisahan aliran ini akan menimbulkan daerah aliran yang di sebut wake. Propeller bekerja di daerah wake yang non uniform sehingga gaya yang flutuatif, perbedaan gaya yang ditimbulkan per satuan luasan menghasilkan perbedaan tekanan di permukaan daun. Hubungan tekanan dengan kebisingan secara matematis yaitu :

$$
I=\frac{P^{2}}{2 \rho c}
$$

dimana,

$\mathrm{P}=$ Tekanan $(\mathrm{Pa})$

$\rho=$ massa jenis $\left(\mathrm{kg} / \mathrm{m}^{3}\right)$

$\mathrm{c}=$ kecepatan gelombang $(\mathrm{m} / \mathrm{s})$

Untuk menentukan Sound Pressure Level (SPL) dari gelombang suara ,yaitu :

$$
S P L=10 \log \frac{I}{I_{0}}
$$

dimana,

$\mathrm{I}=$ Intesitas gelombang $\left(\mathrm{W} / \mathrm{m}^{2}\right)$

Io $=$ Intesitas acuan $\left(\mathrm{W} / \mathrm{m}^{2}\right)$

Skala yang digunakan dalam menentukan tingkat kebisingan merupakan bilangan logaritmik sehingga besarnya kenaikan 1 dB menyatakan kebisingan 10 kali semula. Gelombang suara memiliki kecepatan 4 kali lebih besar dibanding ketika diudara, nilainya dipengaruhi kedalaman, letak perairannya/latitude, suhu lingkungan, dan salinitas perairan. Selama ditransmisikan di laut gelombang ini akan tereduksi oleh lingkungan, tingkat reduksi besar pengaruhnya terhadap frekuensi tinggi.

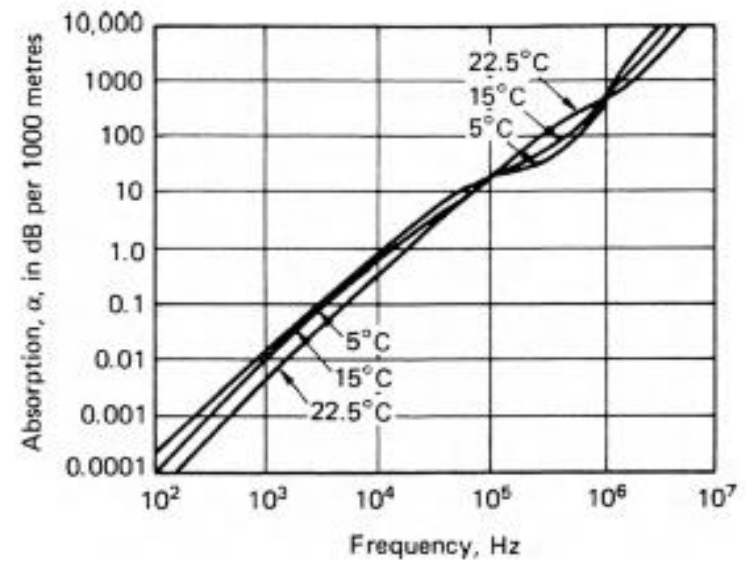

Gambar 2. Penurunan tingkat kebisingan pada frekuensi tertentu selama tranmisi

Gelombang akustik yang di transmisikan oleh kapal selam dalam bentuk kebisingan merupakan gelombang yang kompleks. Untuk memudahkan analisis diperlukan FFT (Fast Fourier Transforms) untuk mengubah gelombang dari domain waktu ke domain frekuensi, sehingga dapat diketahui fase gelombang serta frekuensi mana saja yang dominan terhadap nilai kebisingan.

\section{Persamaan Ffowcs-William Hawkings}

Untuk melakukan kalkulasi kebisingan secara numerik, digunakan persamaan Ffowcs-William Hawkings [6]. Persamaan ini merupakan pengembangan dari analogi akustik yang diperkenalkan oleh Lighthill. Persamaan ini awalnya digunakan dalam simulasi kebisingan di udara, namun memungkinkan dapat digunakan dalam simulasi kebisingan di dalam air. Persamaan FWH didapatkan dari penurunan persamaan kontinuitas dan persamaan navier-stokes. Untuk memperoleh hasil yang akurat dari variabel tekanan, kecepatan, densitas terhadap perubahan waktu dapat digunakan URANS (Unsteady Reynold Average Navier Stokes), LES (Large Eddy Simulation) atau DES (Detached Eddy Simulation) [7]. Selain itu domain yang menjadi objek perhitungan harus memiliki grid yang baik dengan penggunaan time step yang sangat kecil. Bagian kanan dari persamaan FWH terdiri dari : bagian pertama digunakan untuk analisis monopole noise,persamaan kedua untuk dipole noise ,dan persamaan ketiga untuk quadrapole noise.

$$
\begin{gathered}
V^{2} p^{\prime}=\frac{\partial^{2}}{\partial X_{i} \partial X_{j}}\left[\sigma_{i j} H(f)\right]-\frac{\partial}{\partial X_{i}}\left[L_{i} \rho \delta(f)\right]+\frac{\partial}{\partial t}\left[\left(\rho_{0} U_{n}\right) L_{i} \delta(f)\right] \\
U_{n}=\left(1-\frac{\rho}{\rho_{0}}\right) v_{n}+\frac{\rho u_{n}}{\rho_{0}} \\
L_{i}=\rho \delta_{i j}+\rho u_{i}\left(u_{n}-v_{n}\right) \\
u_{n}=u_{i} n_{i}
\end{gathered}
$$

Dimana ;

$$
\begin{array}{ll}
\mathrm{u}_{\mathrm{i}} & =\text { Kecepatan searah sumbu-x } \\
\mathrm{u}_{\mathrm{n}} & =\text { Kecepatan normal terhadap permukaan } \\
\mathrm{v}_{\mathrm{i}} & =\text { Kecepatan local permukaan searah sumbu-x } \\
\mathrm{v}_{\mathrm{n}} & =\text { Kecepatan local permukaan normal terhadap } \\
& \text { permukaan } \\
\mathrm{H}(\mathrm{f}) & =\text { Fungsi Heaviside } \\
\delta(\mathrm{f}) & =\text { Dirac Delta }
\end{array}
$$

Bagian kanan dari persamaan FWH terdiri dari : bagian pertama digunakan untuk analisis monopole noise,persamaan kedua untuk dipole noise, dan persamaan ketiga untuk quadrapole noise [8].

\section{METODOLOGI PENELITIAN}

\section{A. Pengumpulan data dan Studi literatur.}

Studi literatur dilakukan dengan mempelajari berbagai bahan acuan seperti jurnal, buku dan referensi lain seperti Studi sebelumnya. Studi literatur bertujuan untuk membantu dalam memahami dan menganalisis permasahalan pada penelitian ini. Selain itu juga dilakukan penelusuran literatur untuk mendapatkan data penunjang. Data lambung yang 
digunakan didapatkan dari publikasi DARPA, Depatemen Pertahanan Perancis sedangkan data propeller yangdigunakan merupakan propeller yang digunakan PT. PERTAMINA persero.

\section{B. Membuat Model Lambung dan Propeller}

Membuat model lambung dan propeller yang digunakan dalam simulasi, membuat domain dan menentukan boundary condition dari simulasi yang dilakukan.Pada tahapan meshing harus diperhatikan kerapatan dibagian kurvatur dan foil. Turbulensi yang digunakan SST K- $\omega$. Jenis turbulensi ini mampu menganalisis aliran lebih baik [9], sedangkan untuk perhitungan Transient solution,Momentum,Turbulen Kinetic Energy,Spesific Dissipation Rate,Velocity dan Pressure digunakan second order. Simulasi mnggunakan tansientModel lambung dibuat dengan variasi 3,4 dan 5 fin.

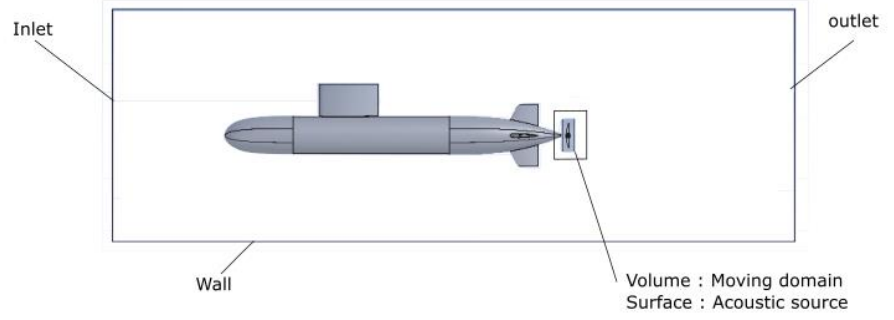

Gambar 3. Domain pada simulasi

\section{C.Meshing}

Pada tahap meshing perlu diperhatikan kualitas, karena memengaruhi keakuratan hasil dan efisiensi penggunaan jumlah elemen dalam studi grid. Kurvatur dan foil harus dipastikan kerapatannya. Juga rotating domain yang digunakan harus dibuat rapat agar fenomena aliran dapat diketahui.

\section{Simulasi Numerik Aliran}

Analisis aliran dilakukan melalui persamaan Navier Stokes, tahapan ini digunakan untuk memperolah jumlah elemen optimum.Sedangkan yang dijadikan acuan dalam studi grid ialah nilai drag pada lambung.

\section{E. Simulasi Numerik Kebisingan}

Analisis kebisingan dilakukan melalui persamaan Ffowcs William Hawkings yang telah disediakan ANSYS Fluent. Disini ditentukan titik yang akan ditinjau yaitu $1 \mathrm{~m}$ di depan propeller dengan daun propeller sebagai sumber kebisingan dengan massa jenis fluida $1028 \mathrm{~kg} / \mathrm{m}^{3}$ kecepatan suara 1500 $\mathrm{m} / \mathrm{s}$ dengan referensi tekanan $1 \mu \mathrm{Pa} .[10]$. Pada simulasi ini digunakan sliding mesh untuk menghasilkan keakuratan hasil [11].

\section{F. Validasi Hasil}

Melakukan perbadingan hasil drag pada simulasi aliran dengan rumus pendekatan hambatan kapal selam [3], sedangkan hasil simulasi kebisingan dibandingkan dengan penelitian sejenis yang menggunakan lambung kapal selam yang memiliki fin dengan propeller pada penelitiannya [7][12]

\section{HASIL DAN PEMBAHASAN}

\section{A. Simulasi Aliran}

Untuk melakukan Analisis kebisingan terlebih dahulu dilakukan simulasi aliran. Simulasi ini diperlukan untuk mengetahui karakteristik aliran disekitar kapal.sehingga didapat kondisi wake yang merupakan daerah propeller bekerja.Simulasi aliran dilakukan pada semua variasi konfigurasi.Pada Analisis aliran ini dilakukan validasi data, ada beberapa parameter penting yang menjadi pertimbangan yaitu : konvergensi dan studi grid.

\section{B. Konvergensi}

Tahap ini proses iterasi akan dikontrol dengan persamaan kendali. Jika hasil perhitungan belum sesuai dengan tingkat error yang telah ditentukan, maka komputasi akan terus berlanjut. Kriteria Root Mean Square (RMS) yang digunakan untuk mengecek konvergensi ditetapkan residual target mencapai $10^{-4}$. Setelah mencapai nilai tersebut harus dipastikan nilai fluktuasi residual sejajar.

\section{Studi Grid}

Studi grid diperoleh pada ukuran elemen 0.02 untuk kapal dan 2 untuk fluida. Dengan settingan yang sama didapatkan jumlah elemen optimum pada 3 fin yaitu 2,307,890, untuk 4 fin yaitu 2,499,879, untuk 5 fin yaitu 2,863,658. Semakin banyak fin pengaruh kejumlah elemen semakin besar, karena bagian foil dan kurvatur harus dijadikan rapat agar hasil simulasi akurat.

Tabel 1.

Grid Independence Pada Kofigurasi 5 Fin

\begin{tabular}{ccc}
\hline \hline Jumlah Element & Force & Selisih $(\%)$ \\
\hline 734275 & 251078 & 6.184134014 \\
$1,434,013$ & 235551 & 4.663109051 \\
$2,863,658$ & 224567 & 1.703723165 \\
$5,675,575$ & 220741 & \\
\multicolumn{4}{c}{ Grid Independence Pada Konfigurasi 4 Fin } \\
\hline \hline Jumlah Element & Force & Selisih $(\%)$ \\
\hline $1,250,979$ & 243586 & 6.340676394 \\
$2,499,879$ & 228141 & 1.25317238 \\
$5,000,450$ & 225282 & \\
& & \\
Grid Independence Pada Konfigurasi 3 Fin \\
\hline \hline Jumlah Element & Force & Selisih $(\%)$ \\
\hline \hline $1,134,841$ & 224333 & 8.34696634 \\
$2,307,890$ & 205608 & 1.542741528 \\
$4,630,764$ & 202436 & \\
\hline \hline
\end{tabular}

Setelah dilakukan nilai force/drag yang telah didapatkan dibandingkan dengan nilai pendekatan hambatan kapal selam yang diberikan berikut ini [3]. 


\begin{tabular}{cc}
\hline \hline Description & $\varepsilon_{\text {hidll }}$ \\
\hline Teardrop shape & 3 \\
Modern shape & $4-5$ \\
PMB hull form & 6 \\
\hline $\mathrm{Cf}_{\text {form }}=\left\{(0.075) /(\log 10 \mathrm{Re}-2)^{2}\right\}$ \\
$\mathrm{C}_{\mathrm{p}}=\mathrm{K}_{\mathrm{p}} \mathrm{C}_{\text {form }}$ \\
$\mathrm{K}_{\mathrm{p}}=\varepsilon_{\text {hull }}(\mathrm{L} / \mathrm{D})^{-1.7}$ \\
$\mathrm{R}_{\text {hull }}=1 / 2 \rho \mathrm{V}^{2} \mathrm{~S} \mathrm{C}_{\mathrm{p}} ;$ \\
$\mathrm{R}_{\text {sail }}=1 / 2 \rho \mathrm{V}^{2} \mathrm{~A}_{\text {frontal }} \mathrm{C}_{\mathrm{d} \text { sail; } ;}$ \\
$\mathrm{R}_{\text {control surface }}=1 / 2 \rho \mathrm{V}^{2} \mathrm{~A}_{\text {plan }} \mathrm{C}_{\mathrm{d} \text { control surface; }}$
\end{tabular}

Intial condition,

Cd sail $=0.2$

Cd control surface $=0.01-0.02$

$\mathrm{R}_{\text {total }}=\mathrm{R}_{\text {hull }}+\mathrm{R}_{\text {controlsurface }}+\mathrm{R}_{\text {sail }}+$ Interference

\section{Simulasi Kebisingan}

Setelah simulasi aliran telah dilakukan, tahap selanjutnya ialah simulasi kebisingan. Nilai wake dipengaruhi bentuk lambung sehingga ketiga variasi akan memiliki wake yang berbeda. Nilai wake merupakan variasi fluktuasi kecepatan. Berikut ini wake pada ketiga variasi.
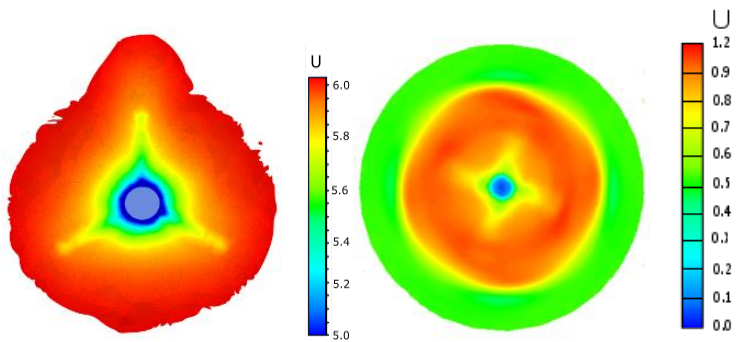

(a)
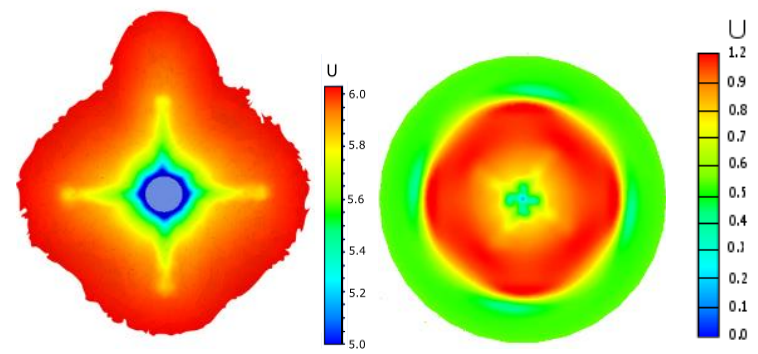

(b)
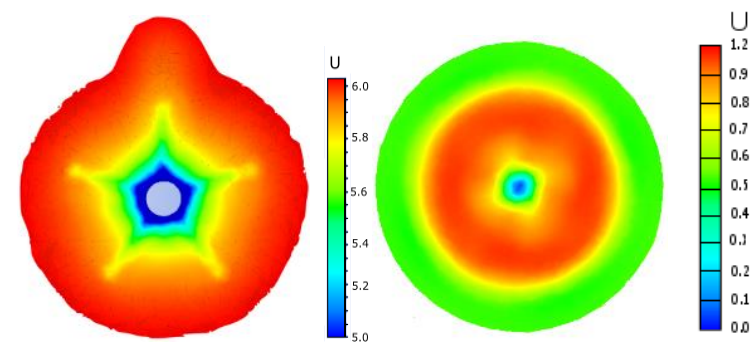

(c)

Gambar 4. Kontur wake sebelum (kiri) dan sesudah (kanan) melewati propeller pada a) 5 fin; b) 4 fin; c) 3 fin

Gambar 4 menunjukan kontur wake yang terjadi setelah aliran melewati fin buritan, region wake yang terbentuk memiliki jumlah yang sama dengan jumlah fin, selain itu terlihat keberadaan sail cukup berpengaruh, karena ganguan (disturbances) aliran yang terbentuk menerus hingga ke buritan sebelum memasuki propellerNilai kontur wake yang berfluktuasi, Kontur ini menunjukan variasi kecepatan dibidang perpotongan single propeller kapal selam. Kecepatan aliran yang terjadi bervariasi $10-90 \%$ kecepatan maju kapal. Perbedaan kecepatan ini menimbulkan perbedaan sudut serang dan gaya lift yang terjadi di propeller sehingga memengaruhi fluktuasi gaya dorong dan torsi yang dihasilkan sepanjang berotasi [13], akibat propeller menerima fluktuasi beban/gaya secara radial saat beroperasi.

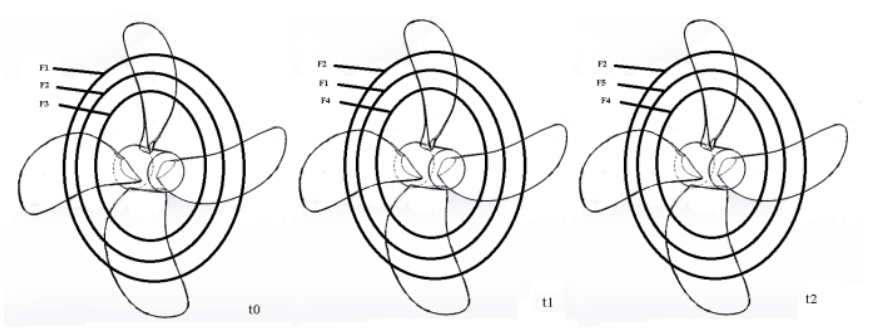

(a)

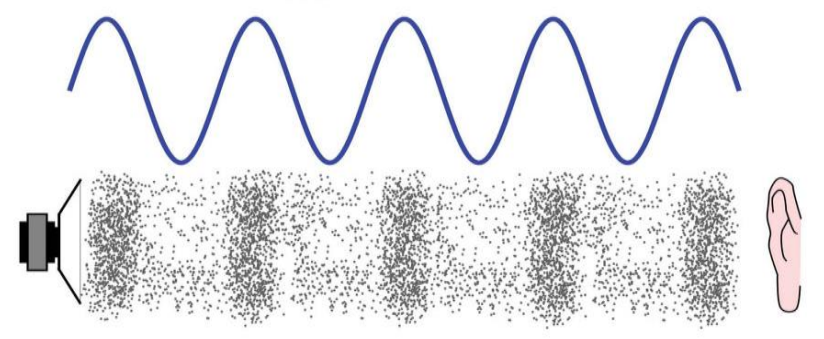

(b)

Gambar 5. Mekanisme perambatan bunyi (a) perbedaan gaya per satuan penampang propeller, (b) bunyi merupakan perbedaan tekanan medium

Nilai tekanan merupakan fungsi gaya, karena gaya tiap posisi $\mathrm{r} / \mathrm{R}$ berbeda maka tekanan yang terjadi tiap satuan penampang luasan akan berbeda. Pada gambar 5 menunjukan perbedaan tekanan ini akan di transmisikan ke lingkungan sehingga terbentuk kebisingan, karena pada dasarnya terjadinya bunyi/noise diakibatkan perbedaan tekanan yang di terjadi pada medium rambat .

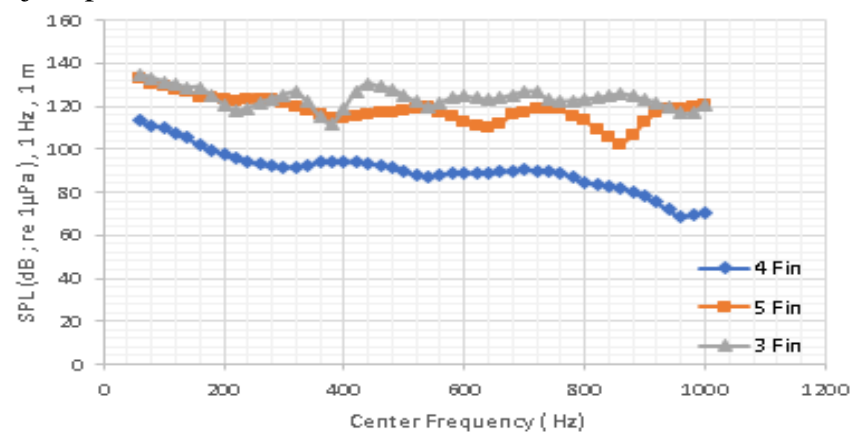

Gambar 6. Hasil simulasi kebisingan

Gambar 6 menunjukan nilai kebisingan tertinggi yang dicapai menggunakan konfigurasi 3 fin sebesar $137 \mathrm{~dB}$ re 1 $\mu \mathrm{Pa} 1 \mathrm{~m}$. Pada konfigurasi 4 fin sebesar $112 \mathrm{~dB}$ re $1 \mu \mathrm{Pa}$ $1 \mathrm{~m}$,dan pada konfigurasi 5 fin sebesar $133 \mathrm{~dB}$ re $1 \mu \mathrm{Pa} 1 \mathrm{~m}$. Hasil kebisingan inidibandingkan dengan hasil penelitian lain yang menggunakan kapal selam berfin dengan propeller pada 
penelitiannya. Dalam simulasi ini referensi tekanan yang digunakan harus dituliskan, pada simulasi ini referensi tekanan suara di air yaitu $1 \mu \mathrm{Pa}$, letak titik tinjauan(receiver) yaitu 1 meter dari propeller, dan nilai kebisingan ini ditinjau sebagai fungsi apa, beberapa referensi meninjau sebagai fungsi kecepatan, sedangkan penulis meninjau sebagai fungsi frekuensi, sehingga di tulis SPL $(\mathrm{dB})$; re $1 \mu \mathrm{Pa}, 1 \mathrm{~Hz}, 1 \mathrm{~m}$. Penulisan ini penting karena memberikan penjelasan terkait acuan hasil pengukuran kebisingan.

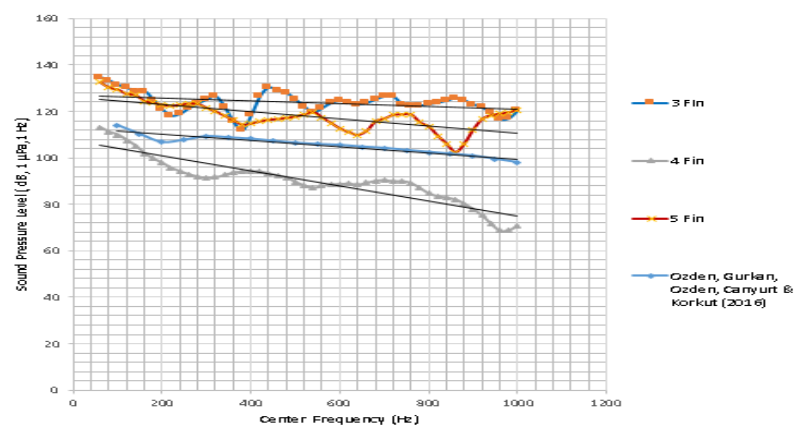

(a)

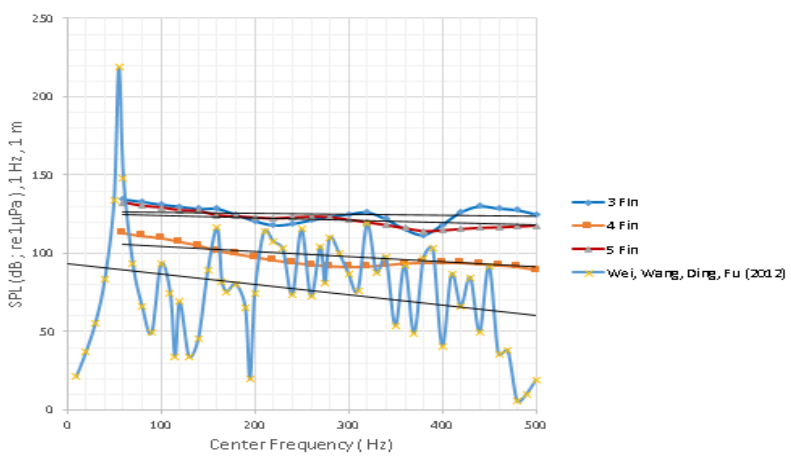

(b)

Gambar 7. Membadingkan hasil a) dengan hasil penelitian [7]; b) dengan hasil penelitian [12].

Gambar 7 (a) membandingkan hasil simulasi dengan hasil yang didapatkan[7], variasi yang dilakukan terletak pada penggunaan data wake(tanpa lambung) dan menggunakan lambung dalam analisis kebisingannya. Selain itu receiver(titik tinjauan) diletakkan didepan,belakang,samping dan atas. Peneliti hanya melakukan peninjauan didepan propeller, sehingga nilai yang dibandingkan hanya pada satu receiver dan didapatkan tren yang sama yaitu nilai kebisingan tertinggi pada frekuensi rendah dan menurun seiring kenaikan nilai frekuenesi. Sedangkan pada gambar 7 (b) membandingkan nilai yang didapat dari simulasi dengan penelitian yang dilakukan [12] Penelitian yang dilakukan [12] menggunakan kapal selam dengan 4 fin dan propeller normal skew berdaun 5. Nilai fluktuatif yang didapatkan peneliti dikarenakan peneliti, memperhitungkan hubungan fluida dengan struktur (Fluid Structure Interaction) sedangkan penulis hanya memperhitungan akibat aliran tanpa interaksi dengan struktur.

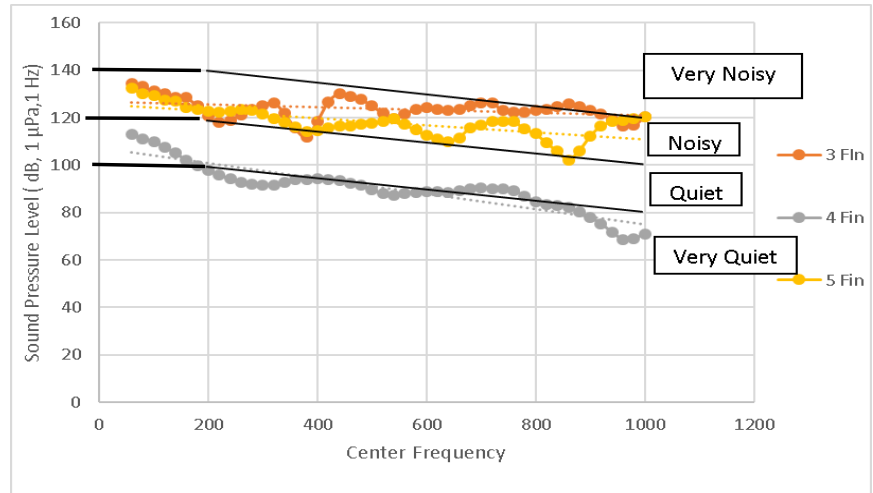

Gambar 8. Parameter kebisingan [14]

Gambar 8 menunjukan parameter yang ditetapkan [14] karakteristik kebisingan dibawah 100 dB dikategorikan sebagai sangat senyap (very quite), diantara $100-120 \mathrm{~dB}$ sebagai senyap (quiet), diantara $120-140 \mathrm{~dB}$ sebagai berisik (noisy) dan lebih dari $140 \mathrm{~dB}$ sebagai sangat berisik (very noisy). Pada simulasi ini ditetapkan kecepatan operasi kapal yaitu $6 \mathrm{~m} / \mathrm{s}$ atau sekitar $12 \mathrm{knot}$, Jika diklasifikasikan berdasarkan klasifikasi kecepatan yang diberikan[3], kecepatan ini termasuk kecepatan normal operasional kapal. Sehingga dapat dikatakan dengan konfigurasi 4 fin-4 daun propeller saat beroperasi normal nilai kebisingan yang dihasilkan sebesar $112 \mathrm{~dB}$ re $1 \mu \mathrm{Pa} 1 \mathrm{~m}$ dikategorikan rendah/quiet. Sedangkan nilai kebisingan yang dihasilkan pada konfigurasi 3 fin- 4 daun propeller sebesar $137 \mathrm{~dB}$ re 1 $\mu \mathrm{Pa} 1 \mathrm{~m}$ dan 5 fin- 4 daun propeller sebesar $132 \mathrm{~dB}$ re $1 \mu \mathrm{Pa}$ $1 \mathrm{~m}$ saat beroperasi normal dikategorikan tinggi/noisy.

\section{KESIMPULAN}

Dari simulasi pengaruh konfigurasi fin pada stern terhadap nilai kebisingan (hydro-acoustic) dapat disimpulkan bahwa :

1. Kontur wake dibelakang fin, menghasilkan jumlah region wake yang sesuai jumlah fin.

2. Nilai kebisingan cenderung menurun pada frekuensi tinggi $(200 \mathrm{~Hz}-1000 \mathrm{~Hz})$

3. Nilai kebisingan tertinggi terjadi di frekuensi rendah $(<200 \mathrm{~Hz})$,hal ini dikarenakan terjadi frekuensi harmonik pertama /resonansi antara frekuensi noise dengan frekuensi natural propeller.

4. Nilai kebisingan pada kecepatan $6 \mathrm{~m} / \mathrm{s}$ yang diperoleh dari simulasi, yaitu untuk konfigurasi 3 fin diperoleh nilai kebisingan tertinggi sebesar $137 \mathrm{~dB}$ re $1 \mu \mathrm{Pa} 1 \mathrm{~m}$ ,sedangkan untuk konfigurasi 4 fin diperoleh $112 \mathrm{~dB}$ re $1 \mu \mathrm{Pa} 1 \mathrm{~m}$, dan untuk konfigurasi 5 fin diperoleh $132 \mathrm{~dB}$ re $1 \mu \mathrm{Pa} 1 \mathrm{~m}$.

\section{DAFTAR PUSTAKA}

[1] P. v Oossanen, Calculation of Performance and Cavitation Characteristics of Propeller Including Effect of Non-Uniform Flow and Viscosity. NSMB Publication, 1970.

[2] J. Carlton, Marine Propeller and propulsion. United State of America: Butteworth Heinemann, 2012.

[3] M. Renilson, "Submarine Hydrodynamic," Springer, 2015.

[4] A. Smith, "Transition, pressure gradient, and stability theory," in International Congress of Applied Mechanics, 1956.

[5] I. Tani, "Boundary Layer Transition," Annu. Rev. Flui Mech., 1969. 
[6] J. F. Williams, "Hydrodyamic Noise," Annu. Rev. Fluid Mech., pp. 197-222, 1969.

[7] T. G. Ozden, M. C., Gurkan, A. Y., Ozden, Y. A., \& Canyurt, "Underwater Radiated Noise Prediction for a Submarine Propepeller in Different Flow Conditions," Ocean Eng. , Elsevier, pp. 488-500, 2016.

[8] S. Mousavi, B., Rahrovi, A., \& Kheradman, "Numerical simulation of tonal and broadband hydrodynamic noises of non cavitating underwater propeller," Polish Marit. Res., pp. 44-53, 2014.

[9] J. Kowalczyk, S., \& Felicjancik, "Numerical and Experimental Propeller Noise Investigations," Ocean Eng. ,Elsevier, 2016.

[10] M. J.Crocker, Encyclopedia of Acoustic. New York: John Wiley and Sons, 1997.

[11] A. Kellet, P., Turan, O., \& Incecik, "A Study of Numerical Ship Underwater Noise Prediction," Ocean Eng. Elsevier, pp. 113-120, 2013.

[12] J. Wei, Y., Wang, Y., Ding, K., \& Fu, "Submarine Underwater Structure-Borne Noise and Flow Noise due to Propeller Excitation," Acoust. Aust., vol. 40, no. 2, pp. 122-127, 2012

[13] D. R. Ross, Mechanics of Underwater Noise. New York: Pergamon Press, 1976.

[14] E. Miasnikov, "Can Russian Strategic SUbmarines Survive at Sea ? The Fundamental Limits of Passive Acoustics," Sci. Glob. Secur., pp. 213-251, 1994. 